\title{
COMPARATIVE ESTIMATION OF PERCENTAGE OF ANTICANCER \& ANTIAGEING ANTIOXIDANTS ISOLATED FROM VARIOUS TEA SAMPLES
}

\author{
Francis Panimathy $A^{1}$ \\ ${ }^{1}$ Department of Chemical Engineering, Dr. M.G.R. Educational \& Research Institute, Chennai, India \\ Email: 1pnmthy@yahoo.co.in
}

\begin{abstract}
Tea is the most commonly consumed beverage in world after water. Whether it is black, green or red tea, all contain polyphenols which gives tea its antioxidant properties. A number of studies have demonstrated the anti-cancer properties of polyphenol. Some studies indeed suggested that tea's polyphenols do reduce the risk of gastric and skin cancer if any one consumes 4 to 6 cups daily. So an attempt is envisaged, in the present study to estimate precisely the percentage of polyphenols in various brands of commercial tea leaf or dust available in market. Based on the percentage of polyphenols, the various brands of tea dust are rated on their therapeutic and medicinal value. In this project work, we have used liquid-liquid extraction using ether as solvent to separate polyphenols.
\end{abstract}

Key words: Polyphenols, antioxidants, anticancer, green tea, tannic acid

\section{INTRODUCTION}

Polyphenols are rich in antioxidants. An antioxidant is a molecule capable of slowing or preventing the oxidation of other molecules. Oxidation is a chemical reaction that transfers electrons from one substance to an oxidizing agent. Oxidation reaction can produce a free radical, which starts a chain reaction that damage cells. Antioxidant terminates these chain reactions by removing a free radical intermediate and inhibits the other oxidation reaction by being oxidized themselves. In this way antioxidant acts as "Free Radical Scavengers" and hence prevents and repair damage done $y$ these free radicals. Health problem such as heart disease, muscular degeneration, diabetes, cancer, cardiovascular problems and some neurological diseases, etc are all enhanced by oxidative damage.

It is a well established fact that people who take 4 to 5 cups of green or black tea per day have lower risk of the above life threatening diseases.

\section{OBJECTIVE}

My present work stems from the efforts to locate a cheap, easily available and ready to use commodity rich in antioxidants and naturally tea tops the list. Now let us be true to ourselves and consent to the fact that most of us cannot start their day without a cup of hot tea, steaming tea. Do we all know that how healthy a tea is?. It is well known that fruits and vegetables are good source of antioxidant; however "What is less well known is the amount of antioxidant present in tea?"

Since any type of tea is rich in polyphenols (powerful antioxidants), the percentage depending on the storage conditions, methods of processing raw tea, weather conditions and soil $\mathrm{pH}$. An attempt is envisaged in the present study to estimate precisely the percentage of polyphenols.

\section{SOURCES OF ANTIOXIDANTS}

Among the well known sources of antioxidants cranberry tops the list followed by strawberry, gooseberry, green tea, freshly brewed coffee and carotene rich carrots. Other sources of antioxidants includes,

Flavonoids - tea, green tea, citrus fruits, red wine, onion and apples

Lycopene - tomatoes, pink grape fruit and watermelon

Vitamin C - oranges, blackcurrants, kiwi fruit, mangoes, broccoli, spinach, capsicum

\section{Structure 1: Polyphenol in tea}

Do antioxidants make tea healthier than water?

Drinking tea is actually better for you than drinking water. Water is essentially replacing fluid. Tea replaces fluid and contains antioxidants. So it got two things going for it. 
The health benefits have been linked to the<smiles>O=c1c(O)cc(C2Oc3cc(O)cc(O)c3CC2O)cc2c([C@@H]3Oc4cc(O)cc(O)c4C[C@H]3O)cc(O)c(O)c12</smiles>

polyphenols content of tea. Green tea contains 30\% to $40 \%$ of water extractable polyphenols, while black tea contains $3 \%$ to $10 \%$.

\section{METABOLITES}

Antioxidant are classified into two broad divisions depending on whether they are soluble in water (hydrophilic) or soluble in lipids (hydrophobic). In general water soluble antioxidants react with oxidants in the cell cytoplasm and the blood plasma, while lipid soluble antioxidant protect cell membranes from lipid peroxidations. These compounds may be synthesized in the body or obtained from diet. The different antioxidants are present at a wide range of concentrations in body fluids and tissues while others are more evenly distributed throughout the body as polyphenols.

Polyphenols are group of substances found in plants, characterized by the presence of more than one phenol group per molecule. Polyphenols are generally further subdivided into hydrolysable tannins which are gallic acid esters of glucose and other sugars and phenyl propanols such as flavonoids and condensed tannins.

How much of tea does anyone need to drink per day to ward off diseases?

One cup of green tea contains approximately $200 \mathrm{mg}$ of flavonoids. Studies indicate having three cups a day over two weeks increases flavonoid levels in blood by $25 \%$. While we know that green tea is very healthy, more evidence is needed to understand how much tea one must consume to really derive complete health benefits. This is because no two human beings are alike each one needs different levels of antioxidants depending on lifestyle, dietary habits, exposure to environment factors like pollution, etc.

\section{METHODOLOGY}

\section{A. Extraction of Polyphenols from Tea Dust:}

1. Tea extract is obtained, by boiling known weight of tea for 2 to 3 minutes in water. The extract is then filtered and cooled to room temperature.

2. Ether is added to the aqueous extract in a separating funnel and shaken well, so that the organic compounds, present in the extract diffuse into either layer. The aqueous layer is removed.

3. To the remaining aqueous layer after two extractions, common salt is added till the solution is saturated with sodium chloride $(\mathrm{NaCl})$, to kick out the traces of organic compounds present if any, (salting out) and now ether is added and shaken well. The ether extract is mixed with earlier ether layers.

4. The total ether extract is washed with $10 \%$ of sodium bicarbonate solution twice and shaken well in a separating funnel, so that all the acidic components present will dissolve, leaving behind the polyphenols and neutral compounds. The aqueous layer will contain sodium salt of extracted acids and this is rejected.

5. Now $10 \%$ of sodium hydroxide is added to the ether layer twice, and shaken well in a separating funnel. Now the phenolic compounds will be converted into water soluble sodium salt of phenols. The polyphenols got converted into soluble sodium salts and will be present in the aqueous layer.

6. To the aqueous layer, hydrochloric acid is added till the solution is acidic (test with blue litmus paper or congo red paper). The phenols are liberated from their sodium salts. Now ether is added and solution is extracted with ether in a separating funnel, so that the liberated phenolic compounds get extracted in the ether layer.

7. The ether layer is dried with anhydrous magnesium sulphate overnight and then the solvent ether is stripped off by heating on a water bath. 


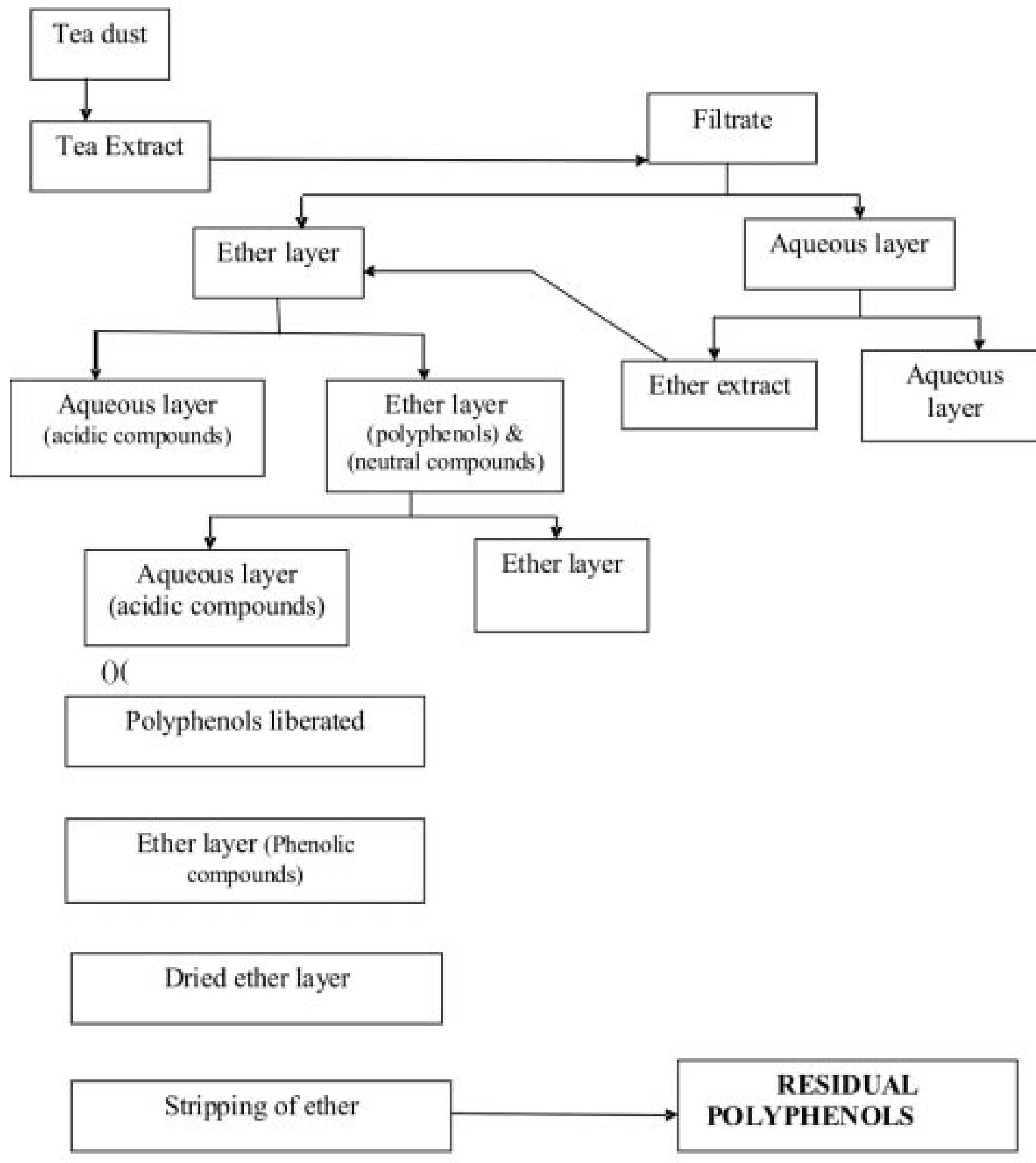

Fig. 1. Flow diagram to show the methodology of extraction of Polyphenol. 
The residual polyphenolic mixture is then accurately weighed and knowing the weight of tea dust taken initially, the percentage of polyphenols, present in the given sample of tea dust can be estimated.

Similar work will be carried out for different brands of tea samples and also by varying the time of extraction of tea with water initially.

Based on this, the percentage of polyphenols, the various brands of tea dust will be rated on their therapeutic and medicinal value.

\section{PRECAUTION}

The longer the time tea dust is boiled with water more and more of injurious and toxic tannic acid will be extracted. Tannic acid (commonly referred to as tannin) is water-soluble polyphenols. They have been reported to be responsible for decreases in feed intake, growth rate, feed efficiency, net metabolizable energy and protein digestibility in experimental animals. Therefore, foods rich in tannins are considered to be of low nutritional value. A simple test to prove the increasing extraction of tannic acid is to add Bismuth chloride to tea decoction after one $\mathrm{min} /$ two $\mathrm{min} /$ three min etc. The increasing darkness of Bismuth tannate precipitate shows conclusively that more and more tannic acid is extracted on longer boiling.

Hence we recommend adding tea dust in boiling water for one min or two min and minimize the extraction of injurious tannic acid.

\section{CALCULATION}

\section{SAMPLE 1:}

AVT Tea dust: 9 gms

Weight of empty beaker $=30.45 \mathrm{gms}$

Weight of empty beaker + polyphenol $=31 \mathrm{gms}$

Weight of polyphenol $=31-30.45$

$=0.55 \mathrm{gms}$

\section{SAMPLE 2:}

3 Roses Tea dust: 9 gms

Weight of empty beaker $=107.75 \mathrm{gms}$

Weight of empty beaker + polyphenols

$$
=108.52 \mathrm{gms}
$$

Weight of polyphenol $=108.52-107.75$

$$
=0.79 \mathrm{gms}
$$

\section{SAMPLE 3:}

Lipton Yellow Tea dust: 9 gms

Weight of empty beaker $=59.80 \mathrm{gms}$

Weight of empty beaker + polyphenol

$$
=60.45 \mathrm{gms}
$$

Weight of polyphenol $=60.45-59.80$

$=0.65 \mathrm{gms}$

\section{RESULT \& CONCLUSION}

Knowing the weight of tea sample taken and the weight of polyphenols obtained we can compute the percentage of polyphenols in a given sample of tea.

\begin{tabular}{|l|c|}
\hline \multicolumn{1}{|c|}{ Name of tea brand } & Percentage of Polyphenol \\
\hline AVT Tea dust & $6.11 \%$ \\
\hline 3Roses Tea dust & $8.55 \%$ \\
\hline Lipton Yellow Tea dust & $7.22 \%$ \\
\hline
\end{tabular}

From the above result, we find that polyphenols in

3 Roses tea > Lipton yellow label tea > AVT tea

\section{ACKNOWLEDGEMENT}

I wish to acknowledge my deep sense of gratitude and heartfelt thanks to my guru and well wisher Dr. K.Srinivasan, who guided me in this project. I also wish to place on record my deep sense of appreciation for Dr. N.Padmanabhan, HOD, Chemical Engg., Dr. M.G.R. University, Chennai, for his unsustained co-operation and whole hearted encouragement.

\section{REFERENCES}

[1] Balentine DA, Wiseman SA, Bouwens LC. The chemistry of tea flavonoids. Crit. Rev. Food Sci. Nutr. 1997; pp. 37: 693-704.

[2] Beecher GR, Warden BA, Merken H. Analysis of tea polyphenols. Proc. Soc. Exp. Biol. Med. 1999; pp. 220:267-270

[3] Bhatia IS, Ullah MR. Polyphenols of tea IV- Qualitative and quantitative study of the polyphenols of different 
organs and some cultivated varieties of tea plant. $\mathrm{J}$. Sci. Food Agric. 1968; pp. 19:535-542.

[4] Oshima Y. Chemical studies on the tannin substances of Formosan tea leaves. Bull. Agr. Chem. Soc. 1936; pp. 12:103

[5] www.nutraingredients.com/...

/Tea-polyphenols-antioxidants-or-prebiotics

[6] www.coffee- tea.co.uk/antioxidants.php

[7] www.deepdyve.com/.../

extraction-of-antioxidants-and-caffeine-from-green-

tea-camelia-ftQZ3GVTKO

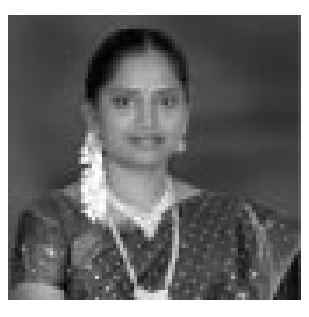

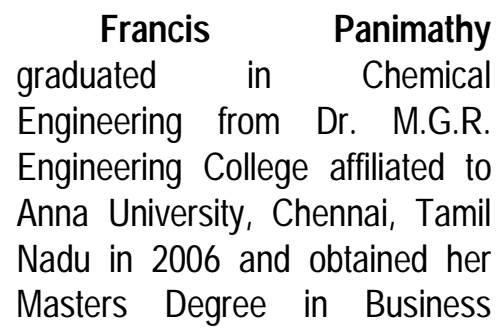

Administration in 2009 from Pondicherry University, Pondicherry. Subsequently she completed a certificate course in 'Safety in Chemical Industries'. The author has been teaching B.Tech, Chemical Engineering courses from 2006 onwards and her subjects include Fluid Mechanics, Chemical Process Calculations, Mass Transfer, Heat Transfer, Chemistry laboratory and Technical Analysis laboratory. The author is currently working as Lecturer in Chemical Engineering at Dr. M.G.R. University, Maduravoyal, Chennai, Tamil Nadu, India. 